US Army Corps of Engineers ${ }_{\circledast}$ Engineer Research and Development Center

\title{
JAIC Predictive Maintenance Dashboard User Manual
}

Joshua Church, LaKenya Walker, and Amy Bednar

August 2021 
The U.S. Army Engineer Research and Development Center (ERDC) solves the nation's toughest engineering and environmental challenges. ERDC develops innovative solutions in civil and military engineering, geospatial sciences, water resources, and environmental sciences for the Army, the Department of Defense, civilian agencies, and our nation's public good. Find out more at www.erdc.usace.army.mil.

To search for other technical reports published by ERDC, visit the ERDC online library at https://erdclibrary.on.worldcat.org/discovery. 


\section{JAIC Predictive Maintenance Dashboard User Manual}

Joshua Church, LaKenya Walker, and Dr. Amy Bednar

Information Technology Laboratory

US Army Engineer Research and Development Center

3909 Halls Ferry Road

Vicksburg, MS 39180-6199

Final Report

Approved for public release; distribution is unlimited.

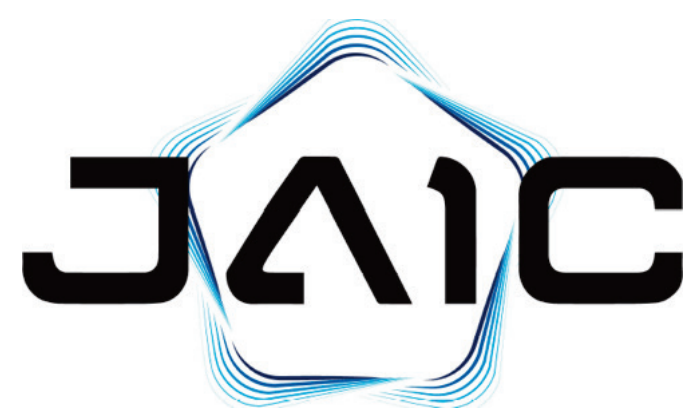

Prepared for Joint Artificial Intelligence Center

Fort Meade, MD 20755

Under MIPR HC1085015834 


\section{Abstract}

This manual is intended for new users with minimal or no experience with using the JAIC Predictive Maintenance Dashboard (JPD). The goal of this document is to give an overview of the main functions of JPD. The primary focus of this document is to demonstrate functionality.

Every effort has been made to ensure this document is an accurate representation of the functionality of the JPD. For additional information about this manual, contact ERDC.JAIC@erdc.dren.mil.

DISCLAIMER: The contents of this report are not to be used for advertising, publication, or promotional purposes. Citation of trade names does not constitute an official endorsement or approval of the use of such commercial products. All product names and trademarks cited are the property of their respective owners. The findings of this report are not to be construed as an official Department of the Army position unless so designated by other authorized documents.

DESTROY THIS REPORT WHEN NO LONGER NEEDED. DO NOT RETURN IT TO THE ORIGINATOR. 


\section{Contents}

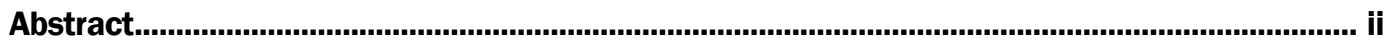

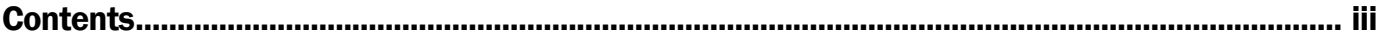

Figures and Tables..............................................................................................................

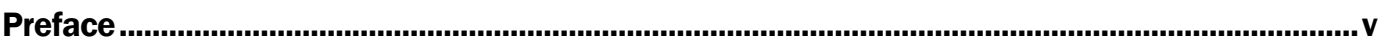

Acronyms and Abbreviations ..................................................................................................... vi

1 Introduction............................................................................................................................ 1

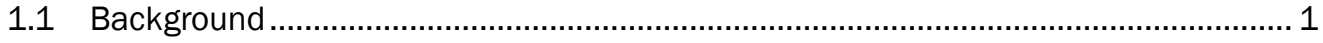

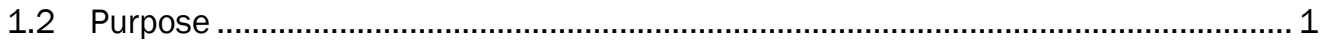

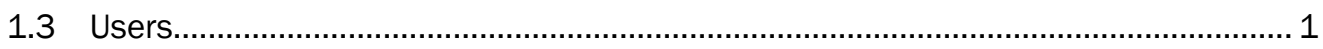

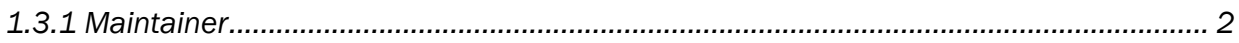

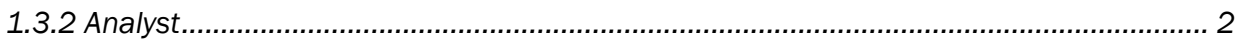

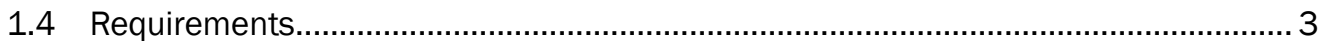

1.4.1 Recommended operating systems............................................................................. 3

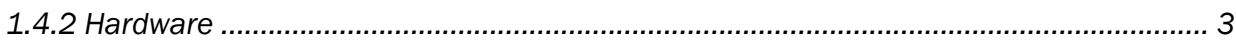

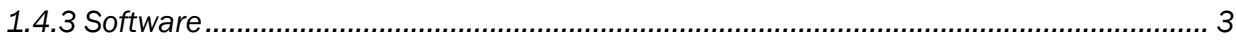

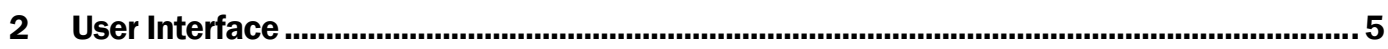

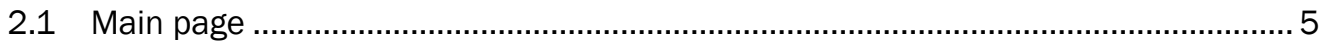

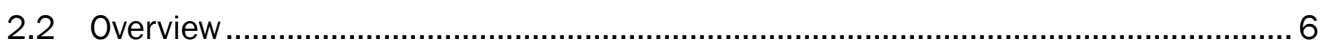

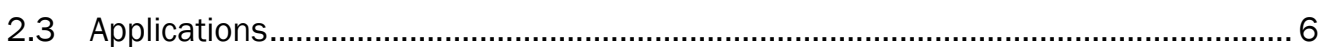

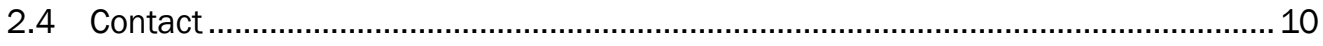

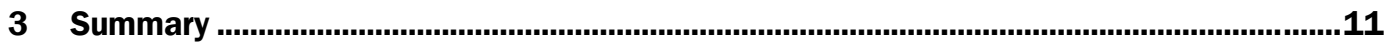

4 References ......................................................................................................................12

Report Documentation Page.......................................................................................................13 


\section{Figures}

\begin{tabular}{|c|c|}
\hline & ge .. \\
\hline 2 & Tabs detail...... \\
\hline & 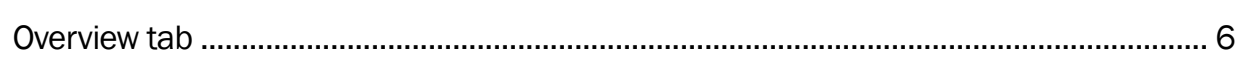 \\
\hline & Application tabs \\
\hline & AWE tab \\
\hline & 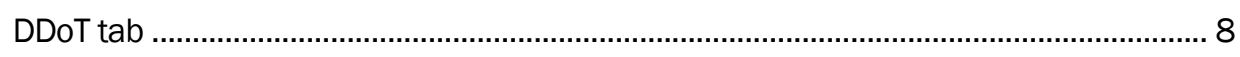 \\
\hline 7 & ILARA tab .................. \\
\hline 8 & Tool tab options ........ \\
\hline & Launch button.......... \\
\hline & 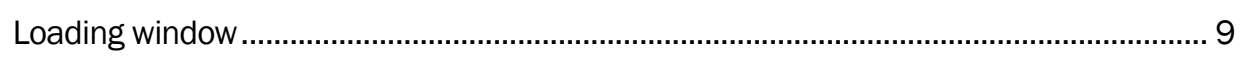 \\
\hline & intact information.. \\
\hline
\end{tabular}




\section{Preface}

This study was conducted under MIPR HC1085015834 under Project "ERDC PMx Product Transition to the Joint Artificial Intelligence Center (JAIC) Joint Common Foundation (JCF)." The technical monitor was Dr. Maria Niki Goerger.

The work was performed by the Computational Analysis Branch of the Computational Science and Engineering Division, U.S. Army Engineer Research and Development Center, Information Technology Laboratory (ERDC-ITL). At the time of publication, Mr. Joshua Church was Acting Branch Chief; Dr. Jeffrey Hensley was Division Chief; and Dr. Robert Wallace was Technical Director for the Engineered Resilient Systems (ERS) program. The Deputy Director of ERDC-ITL was Dr. Jackie Pettway, and the Director was Dr. David Horner.

COL Teresa A. Schlosser was the Commander of ERDC, and Dr. David W. Pittman was the Director. 


\section{Acronyms and Abbreviations}

\begin{tabular}{|l|l|}
\hline Term & Definition \\
\hline AI & Artificial Intelligence \\
\hline AWE & Associated Words Explorer \\
\hline DDoT & Data Documentation Tool \\
\hline DoD & Department of Defense \\
\hline ERDC & Engineer Research and Development Center \\
\hline ERS & Engineered Resilient Systems \\
\hline GUI & Graphical User Interface \\
\hline ILARA & Iterative Learning Algorithms for Records Analysis \\
\hline ITL & Information Technology Laboratory \\
\hline JAIC & Joint Artificial Intelligence Center \\
\hline JCF & Joint Common Foundation \\
\hline JL & Joint Logistics \\
\hline JPD & JAIC PMx Dashboard \\
\hline LTS & Long Term Support \\
\hline NLP & Natural Language Processing \\
\hline NMI & National Mission Initiatives \\
\hline PMx & Predictive Maintenance \\
\hline
\end{tabular}




\section{Introduction}

\subsection{Background}

The Joint Artificial Intelligence Center (JAIC) was established by the Department of Defense (DoD) to accelerate the DoD's adoption and integration of artificial intelligence (AI) to achieve mission impact at scale (Joint Artificial Intelligence Center, n.d.). As part of this effort, JAIC commenced a multitude of National Mission Initiatives (NMIs), ranging from predictive maintenance efforts to enterprise hosting solutions for AI-ready applications. The US Army Engineer Research and Development Center (ERDC), Information Technology Laboratory (ITL) partnered with the JAIC to develop tools in support of the JAIC Joint Logistics (JL)/Predictive Maintenance (PMx) NMI. The mission of JAIC JL/PMx NMI is to use artificial intelligence, deep learning, and predictive analytics to forecast major issues with military vehicles, for instance the H-6o helicopter platform, to better enable services to respond to anticipated failure.

\subsection{Purpose}

The JAIC PMx Dashboard (JPD) enables users to access tools, documentation, and video tutorials in a single location. The JPD provides users the ability to launch the following tools: Associated Words Explorer (AWE), JAIC Data Documentation Tool (DDoT), and Iterative Learning Algorithms for Records Analysis (ILARA). AWE uses natural language processing (NLP) techniques to find associated words, misspellings, patterns, acronyms, and other artifacts within maintenance logbook data that would be difficult to find otherwise. DDoT includes a user-friendly graphical user interface (GUI), which provides access to a centralized location to explore the data history, specifications, and documentation for the multiple datasets used to perform H-6o maintenance between the Joint Services. ILARA is responsible for labeling maintenance logbook entries with (1) the component being repaired and (2) the types of maintenance being performed. Each tool's respective user manual can be found in the JPD.

\subsection{Users}

This section discusses the different types of user. 


\subsubsection{Maintainer}

\subsubsection{AWE}

A maintainer should utilize AWE to understand the commonality in vernacular among the different maintainers. For example, one maintainer may use the word "bld" as a shorthand version of "blade." AWE allows maintainers to find these patterns to better understand descriptions of maintenance events.

\subsubsection{DDoT}

A maintainer should utilize DDoT to gain useful information on the history, specifications, and usage of the H-6o data through a user-friendly GUI.

\subsubsection{ILARA}

A maintainer should utilize ILARA to automatically label the following fields: SCD1 (Potential Termination), SCD2 (Failure Classification), and RFG (Aircraft model designation series).

\subsubsection{Analyst}

\subsubsection{AWE}

An analyst should utilize the output from AWE to find patterns within the free-text fields of the logbook data. An analyst may need guidance from a subject matter expert in selecting key words to choose.

\subsubsection{DDoT}

An analyst should utilize DDoT to gain useful information on the history, specifications, and usage of the H-6o data in a user-friendly GUI.

\subsubsection{ILARA}

An analyst should utilize the output from ILARA, which will now have automatically labeled fields (i.e., SCD1, SCD2, and RFG), which can be analyzed to find trends in the maintenance logbook over specific lengths of time. 


\subsection{Requirements}

This section covers the following requirements to use the JPD: operating system, hardware, and software.

\subsubsection{Recommended operating systems}

- Windows: Windows 10

- Mac: macOS Sierra or newer

- Linux: Ubuntu >=16.04 Long Term Support (LTS).

\subsubsection{Hardware}

For each tool, it is recommended to have a computer less than five years old. The following are specific requirements for each tool and should be used as a guideline.

\subsubsection{AWE}

- Processor: minimum $2 \mathrm{GHz}$; recommended $3 \mathrm{GHz}$

- Hard Drive: minimum $32 \mathrm{~GB}$; recommended $64 \mathrm{~GB}$

- Memory (RAM): minimum 4 GB; recommended 8 GB.

\subsubsection{DDoT}

- Processor: minimum $2 \mathrm{GHz}$; recommended $3 \mathrm{GHz}$

- Hard Drive: minimum $16 \mathrm{~GB}$; recommended $32 \mathrm{~GB}$

- Memory (RAM): minimum 2 GB; recommended 4 GB.

\subsubsection{ILARA}

- Processor: minimum $2 \mathrm{GHz}$; recommended $3 \mathrm{GHz}$

- Hard Drive: minimum $32 \mathrm{~GB}$; recommended $64 \mathrm{~GB}$

- Memory (RAM): minimum 8 GB; recommended 64 GB.

\subsubsection{Software}

Supported browsers are

- Google, and

- Chrome Firefox. 
Other important software includes

- R;

- RStudio; and

- Java 8, 9, 10, 11, 12, or 13 .

○ This is required for both AWE and ILARA. 


\section{User Interface}

\subsection{Main page}

Once the JPD loads, the user is presented with the following interface (see Figure 1):

Figure 1. Main page.

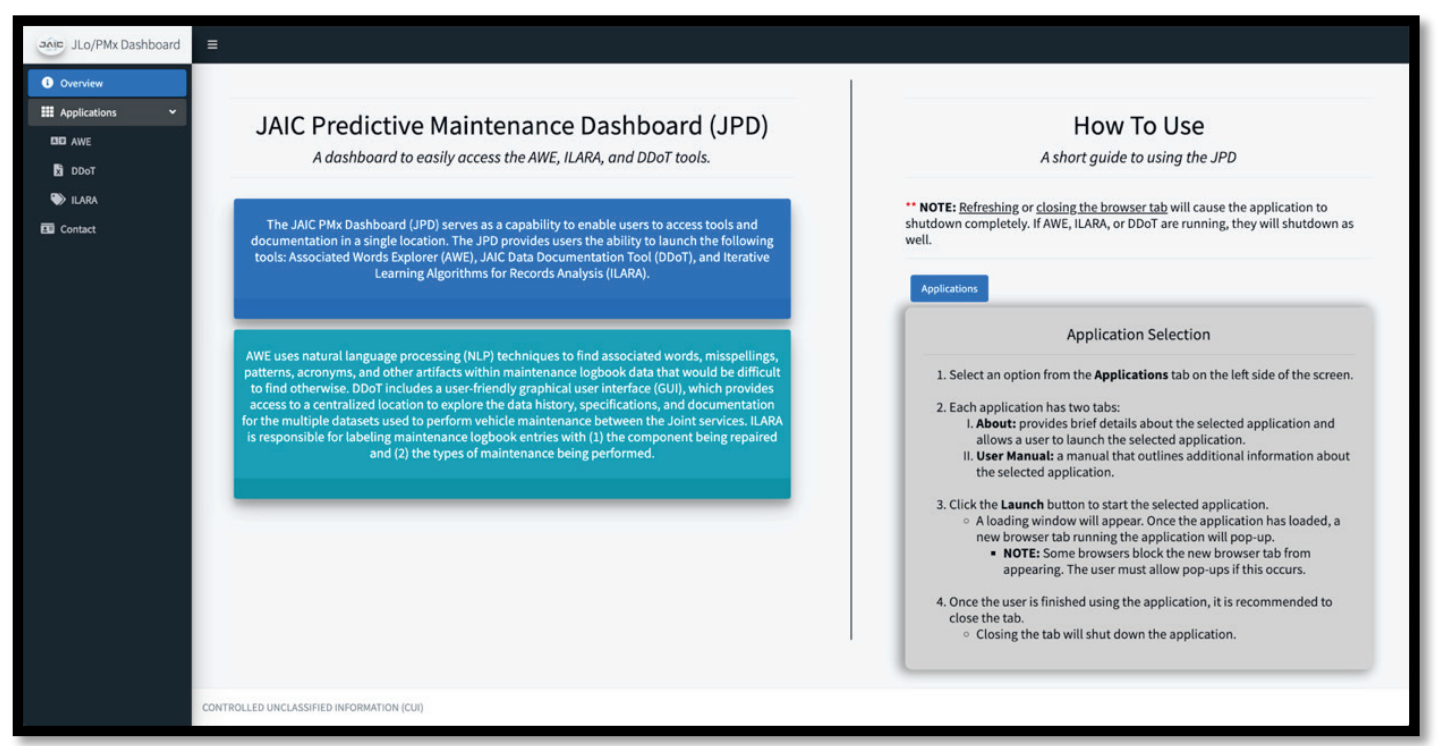

On the left side of the screen, the user can select different tab options.

NOTE: When using the JPD, refreshing or closing the browser tab will cause the application to shut down. If any of the applications (i.e., AWE, DDoT, or ILARA) are running, the application will shut down as well.

There are three main tabs (see Figure 2) available for the user to select: Overview, Applications, and Contact. There are three sub tabs nested within the Applications tab available for the user to select: AWE, DDoT, and ILARA. 
Figure 2. Tabs detail.

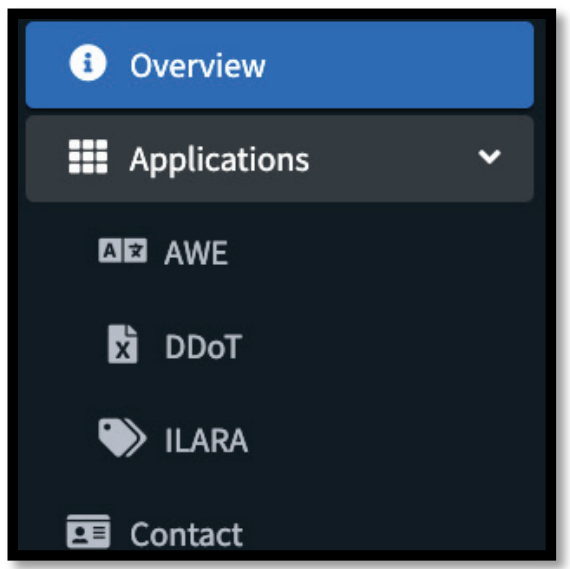

Information about each tab can be found in the following sections.

\subsection{Overview}

The Overview tab (see Figure 3) contains information on the purpose of JPD and brief instructions on how to use the software. These instructions are designated for the Applications section.

Figure 3. Overview tab.

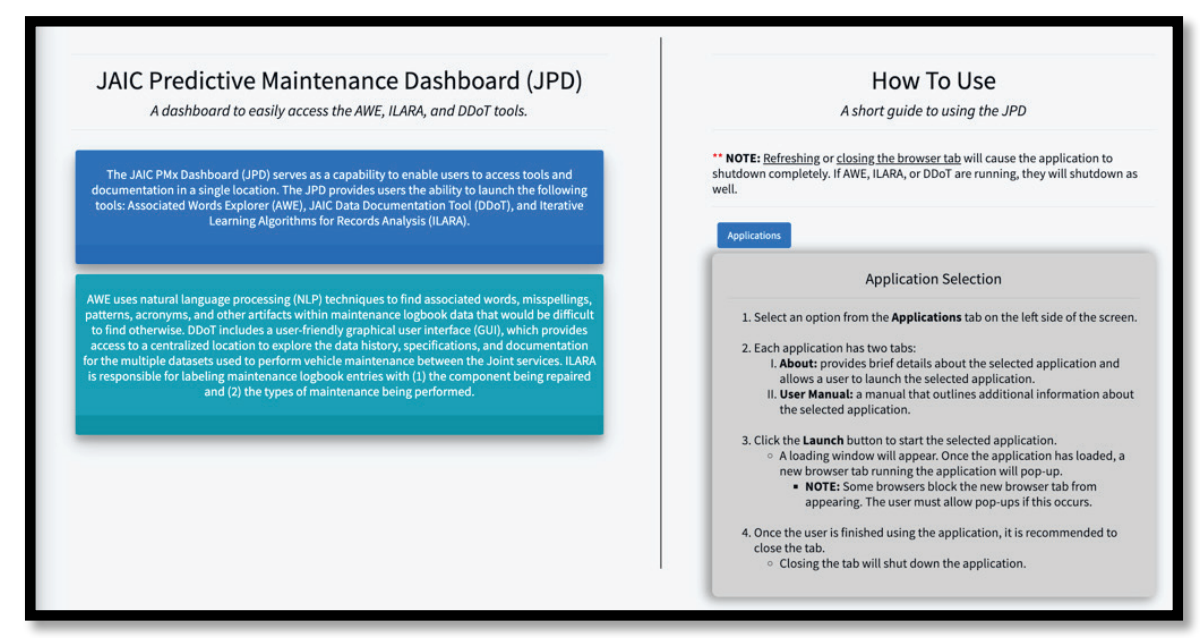

\subsection{Applications}

The Applications tab (see Figure 4) allows the user to access tools and documentation for AWE, DDoT, and ILARA. The following discusses how the user can launch each of the available tools and view their respective user manuals. 
Figure 4. Application tabs.

\section{\# Applications}

\section{A) AWE}

\section{x' DDoT}

\section{ILARA}

For the Associated Words Explorer tool, the user should select the AWE tab. Figure 5 is a screenshot of the page for this tool.

Figure 5. AWE tab.

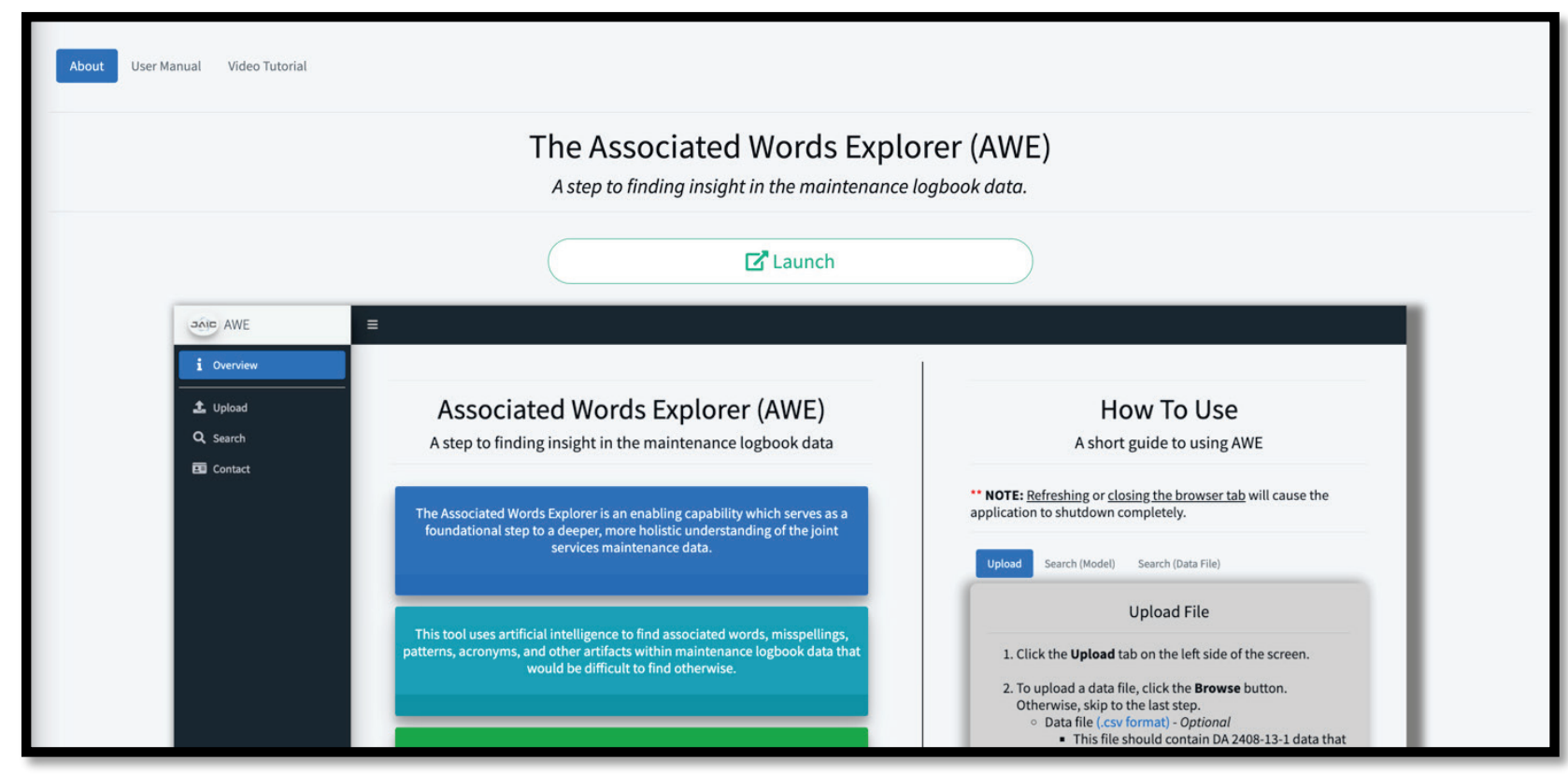

For the JAIC JL/PMx Data Documentation Tool, the user should select the DDoT tab. Figure 6 is a screenshot of the page for this tool. 
Figure 6. DDoT tab.

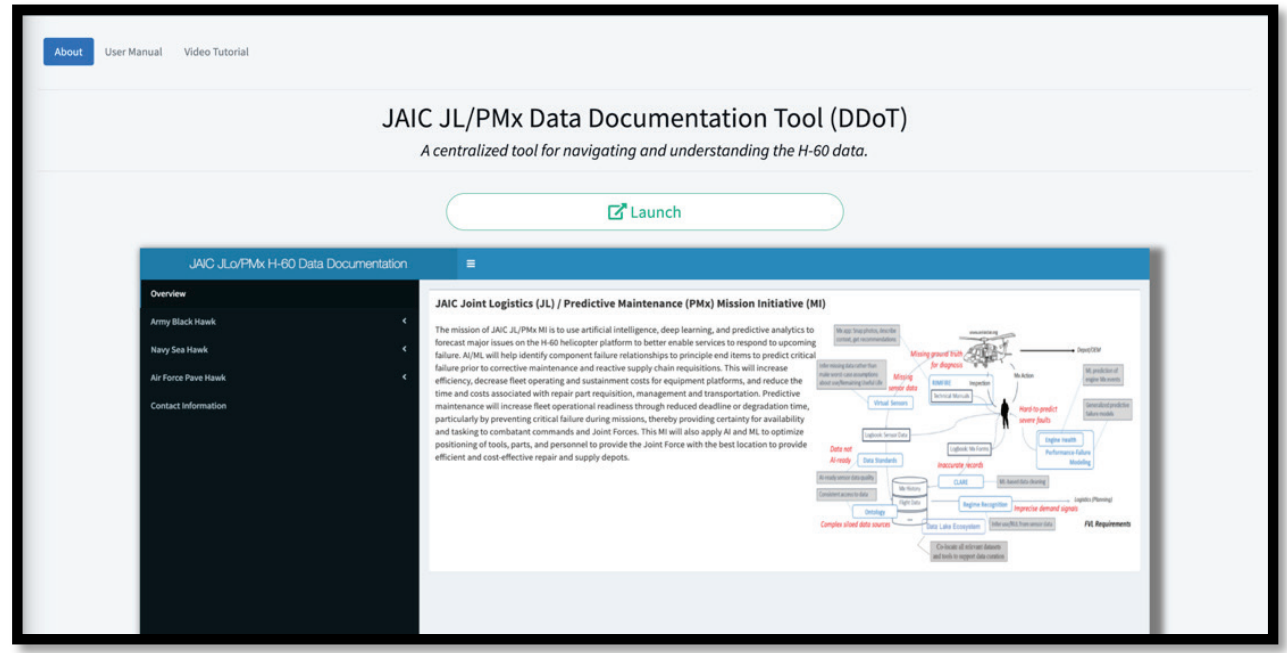

For the Iterative Learning Algorithm for Records Analysis tool, the user should select the ILARA tab. Figure 7 is a screenshot of the page for this tool.

Figure 7. ILARA tab.

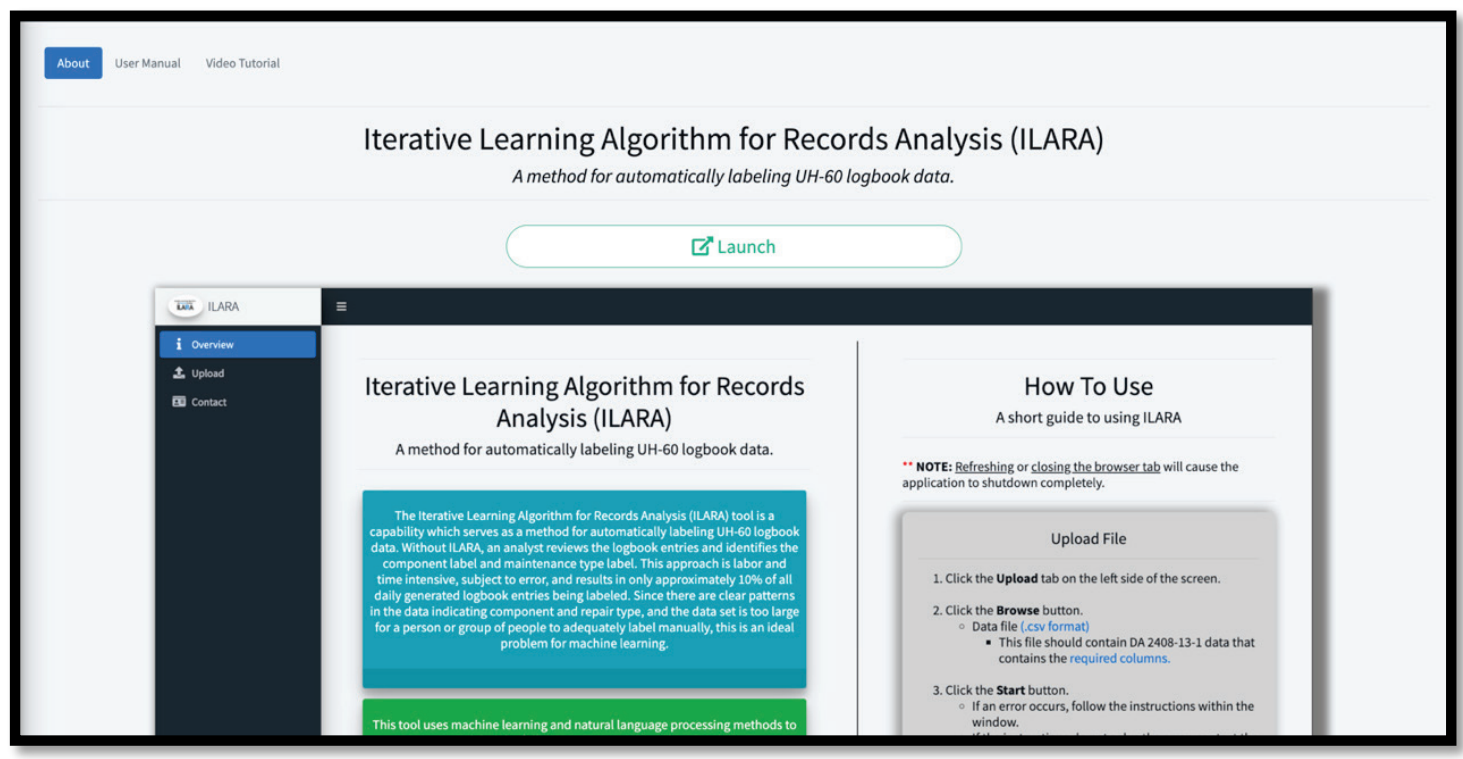

In the top-left corner of each tool's page, there are three available tab options (see Figure 8) for the user to select:

- About-a page that provides a short description about the tool, along with a screenshot of the selected tool's user interface 
- User Manual-a document that assists the user with various functional components of the selected tool

- Video Tutorial-a short video tutorial that outlines key features from the user manual.

Figure 8. Tool tab options.

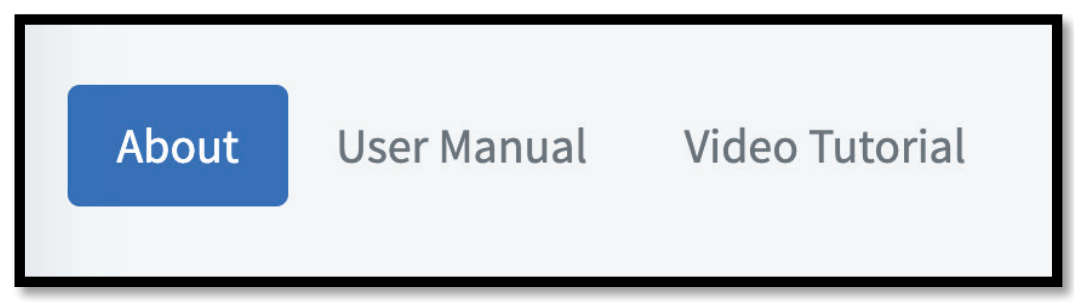

To start the selected tool, perform the following steps:

1. Click the About tab.

2. Click the Launch button (see Figure 9).

Figure 9. Launch button.

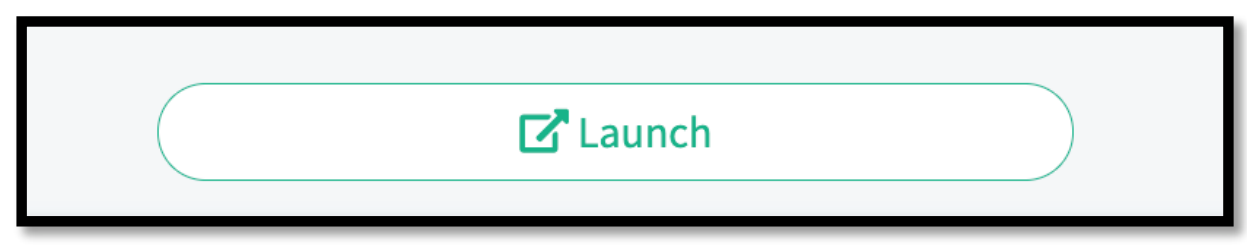

a. Once the user clicks the Launch button, the following loading window (see Figure 10) will appear.

Figure 10. Loading window.

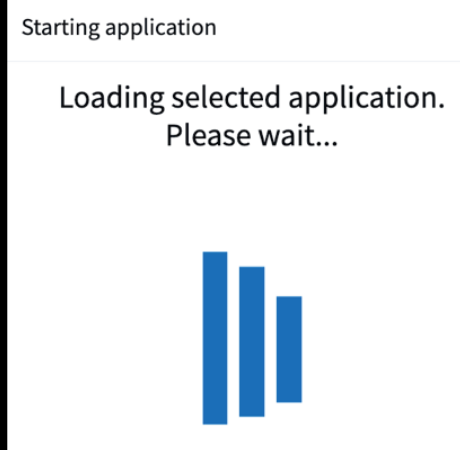


b. Once the tool loads, the user interface will appear in a new browser tab.

NOTE: The user's browser may prevent the tool from launching in a new tab due to the user's security settings. If this occurs, the user must enable pop-ups for the selected application and step through this process again.

To view the tool's user manual, click the User Manual tab. The tool's user manual can now be accessed by the user.

To view the tool's video tutorial, click the Video Tutorial tab. The tool's video tutorial can now be accessed by the user.

\subsection{Contact}

The Contact tab (see Figure 11) provides the contact information for the developer of the JPD tool.

Figure 11. Contact information.

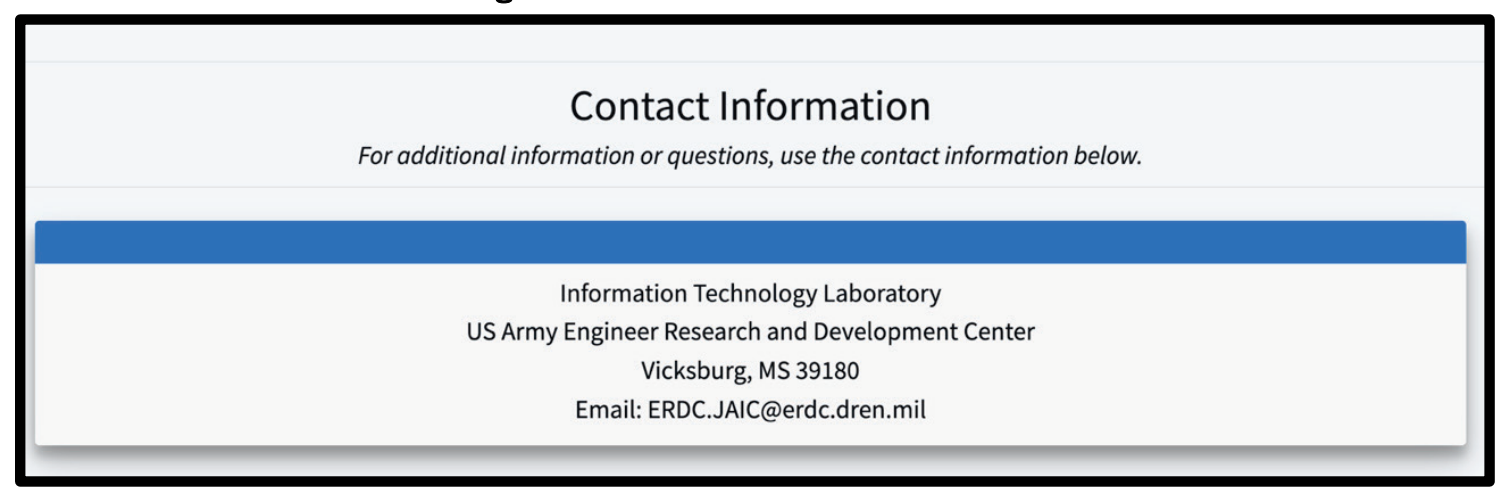




\section{Summary}

JPD was created as a central location for users as to access JAIC tools and documentation. The JPD provides users the ability to launch AWE, DDoT, and ILARA. The greatest benefit of consolidating the tools in a centralized location is that it allows for quicker and simpler access. 


\section{References}

Joint Artificial Intelligence Center. n.d. "About the JAIC: The JAIC Story." Accessed June 25, 2021. https://www.ai.mil/about.html. 


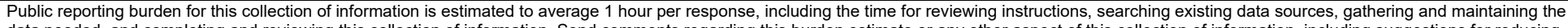

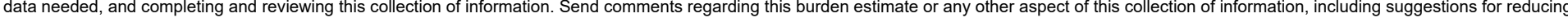

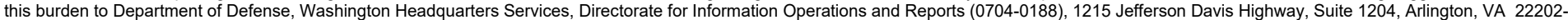

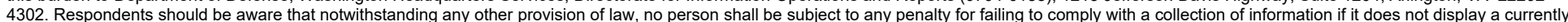
valid OMB control number. PLEASE DO NOT RETURN YOUR FORM TO THE ABOVE ADDRESS.

\begin{tabular}{l|l} 
valid OMB control number. PLEASE DO NOT RETURN YOUR FORM TO THE ABOVE ADDRESS. \\
\hline 1. REPORT DATE (DD-MM-YYYY) & 2. REPORT
\end{tabular}

\begin{tabular}{|c|c} 
August 2O21 & Final Report \\
\hline
\end{tabular}

\section{TITLE AND SUBTITLE}

Final Report

JAIC Predictive Maintenance Dashboard User Manual

5a. CONTRACT NUMBER

5b. GRANT NUMBER

5c. PROGRAM ELEMENT

6. AUTHOR(S)

Joshua Church, LaKenya Walker, and Dr. Amy Bednar

\section{5d. PROJECT NUMBER}

5e. TASK NUMBER

5f. WORK UNIT NUMBER

7. PERFORMING ORGANIZATION NAME(S) AND ADDRESS(ES)

U.S. Army Engineer Research and Development Center (ERDC)

Information Technology Laboratory (ITL)

Waterways Experiment Station, 3909 Halls Ferry Road

Vicksburg, MS 39180-6199

8. PERFORMING ORGANIZATION REPORT NUMBER

ERDC/ITL SR-21-9

\section{SPONSORING / MONITORING AGENCY NAME(S) AND ADDRESS(ES)}

Joint Artificial Intelligence Center

Defense Information Systems Agency

DISA General Fund Division

6910 Cooper Ave.

Fort Meade, MD 20755

10. SPONSOR/MONITOR'S ACRONYM(S)

JAIC

11. SPONSOR/MONITOR'S REPORT NUMBER(S)

\section{DISTRIBUTION / AVAILABILITY STATEMENT}

Approved for public release; distribution is unlimited.

\section{SUPPLEMENTARY NOTES}

MIPR HC1085015834

\section{ABSTRACT}

This manual is intended for new users with minimal or no experience with using the JAIC Predictive Maintenance Dashboard (JPD). The goal of this document is to give an overview of the main functions of JPD. The primary focus of this document is to demonstrate functionality.

Every effort has been made to ensure this document is an accurate representation of the functionality of the JPD. For additional information about this manual, contact ERDC.JAIC@erdc.dren.mil.

\section{SUBJECT TERMS}

Vehicles, Military-Maintenance and repair-Predictive analytics, Data processing, Computer programs, Artificial intelligence

\begin{tabular}{|c|c|c|}
\hline \multicolumn{3}{|c|}{ 16. SECURITY CLASSIFICATION OF: } \\
\hline $\begin{array}{l}\text { a. REPORT } \\
\text { Unclassified }\end{array}$ & $\begin{array}{l}\text { b. ABSTRACT } \\
\text { Unclassified }\end{array}$ & $\begin{array}{l}\text { c. THIS PAGE } \\
\text { Unclassified }\end{array}$ \\
\hline
\end{tabular}

\begin{tabular}{|c|c|c|}
$\begin{array}{c}\text { 17. LIMITATION } \\
\text { OF ABSTRACT }\end{array}$ & $\begin{array}{c}\text { 18. NUMBER } \\
\text { OF PAGES }\end{array}$ & \\
\cline { 3 - 3 } SAR & 21 & \\
\end{tabular}

19a. NAME OF RESPONSIBLE PERSON 